\title{
Ferramentas para a Intervención na Lectura Global de Persoas con TEL
}

\section{Tools in global reading intervention for people with Specific languaje disorder}

\author{
Beatriz López, Leticia Sambade, Berta Fraga \\ Asociación DISMACOR
}

\begin{abstract}
Resumo
Neste estudio explóranse as relacións entre os trastornos específicos da linguaxe e adquisición da lectura. Con esta finalidade avalíanse a un grupo de suxeitos de entre 7 e 15 anos que foron clasificados dentro de Trastornos específicos da linguaxe. Realízase unha avaliación inicial da súa competencia lectora efectuando posteriormente unha intervención dirixida a mellorar os procesos lectores grazas o emprego de programas baseados na lectura global, para finalizar efectuando unha avaliación final na que se recollen os cambios percibidos. Os resultados mostran que os suxeitos que apoian a aprendizaxe seguindo procesos de lectura global mostran importantes avances.

Palabras clave: Trastornos Específico da Linguaxe, lectura globalizada, inclusión, normalización.
\end{abstract}

\begin{abstract}
This study shows relations between specific language disorder and reading skills. With this aim, we evaluate a group of subjects between 7 and 15 years old with specific language disorder. An initial evaluation of reading is made, then a direct intervention is set to improve reading processes with a global reading program, to finalize effecting a final evaluation where we detected the changes. The studio shows global reading improves the results in people with this disorder.

Keywords: Specific language disorder, global reading, inclusion, normalization.
\end{abstract}

\section{Introdución}

O Trastorno específico da linguaxe (TEL) está caracterizado por un atraso clinicamente significativo na adquisición da linguaxe dun suxeito a pesar de contar cunha intelixencia situada entre as marxes propios da idade, unha audición adecuada e as oportunidades educativas necesarias. Pode ser reflexo dun desenvolvemento cerebral anormal que se inicia prenatalmente (Whitehouse, Bishop, Ang, Pennell e Fisher, 2011). Con índices de prevalencia do 7,4\% da poboación de ao redor de 5 anos de idade, pode estar presente ao longo de todo o ciclo vital, limitando seriamente o futuro rendemento académico así como o desenvolvemento socioemocional do neno.

A neuropsicoloxía conceptualiza o TEL como unha patoloxía cuxa extensión excede do ámbito lingüístico e afecta a outros dominios cognitivos verbais e non verbais (Hill, 2001). En xeral, os traballos en nenos con TEL describen problemas en memoria de traballo verbal (Montgomery, 2000; Williams et al., 2000; Montgomery e Evans, 2009; Henry et al., 2012), en fluidez verbal e non verbal, inhibición non verbal, planificación non verbal (Henry et al., 2012) e en procesos de categorización (Buiza-Navarrete et al., 2007).

$\mathrm{O}$ establecemento de subtipos de TEL pon de manifesto que é un construto que aglutina diversos fallos lingüísticos (Rapin e Allen, 1987; Castro-Rebolledo, Giraldo-Prieto, Fincapé-Henao, Lopera e Pineda, 2004; Acosta, Ramírez e Hernández, 2013) que poderían corresponderse cunha deterioración dos mecanismos nos que se asenta a aprendizaxe e/ou a automatización das regras gramaticais, ou ben poderían estar relacionadas con déficits en dominios de natureza non lingüística, pero transversais ao funcionamento cognitivo, como a atención, a velocidade de procesamento ou a memoria. Estas funcións complementarias non lingüísticas estímanse necesarias para a adecuada adquisición da linguaxe e por tanto para a posterior adquisición da lectoescritura.

Foron varios os traballos que hipotizaron sobre a relación entre trastornos da linguaxe e os problemas de lectura. Snowling, Bishop e Stothard (2000) realizaron un estudo lonxitudinal con nenos diagnosticados ao comezo da súa escolarización con trastorno específico da linguaxe no que se atoparon importantes dificultades en lectura mecánica e comprensión lectora. Doutra banda, Catts, Fey, Tomblin e Zhang (2002) atoparon que o 60\% dos nenos con diagnóstico de TEL en preescolar tiñan problemas de lectura posteriormente. Por tanto, as alteracións na linguaxe poderían incidir, tanto na adquisición da lectura como na comprensión lectora.

No presente traballo empregarase a lectura globalizada como método para a adquisición da escritura, debido as vantaxes desta forma de aprendizaxe, en canto á espontaneidade coa que ocorre como proceso e a que se desenvolve vinculada ao obxecto no contexto de uso. Ademais permite sistematizar estratexias e axudas para garantir que os nenos adquiran a lectura. Deste xeito á memoria visual, os nenos recoñecen letras, mesmo frases e relaciónanas coas imaxes. Tras moitas repeticións, os nenos xa están preparados para ler frases ou, mesmo, textos con esas palabras aprendidas. É un método máis natural, porque segue o mesmo proceso que a aprendizaxe da linguaxe, que se basea en repetir as palabras que ouvimos continuamente. Ademais, o neno sente interesado por aquilo que ten sentido, o que lle 
axuda a ter unha lectura máis fluída e comprensiva desde o principio.

A hipótese do noso traballo é que o emprego de programas de intervención en lectura global mellora a competencia lectora dos suxeitos con TEL.

\section{Método}

\section{Participantes}

Seleccionouse unha mostra de tres rapaces con Trastorno específico da linguaxe que non adquiriran a lectura. Todos eles pertencentes a familias de nivel sociocultural medio-baixo e escolarizados en centros ordinarios pertencentes á área metropolitana dunha urbe galega duns 225.000 habitantes. Dous deles non teñen irmáns e nun caso é o mediano dun grupo de tres En tódolos casos iniciouse a adquisición da lecto-escritura empregando métodos fonéticos sen éxito.

Táboa 1.

Idades e sexo dos suxeitos

\begin{tabular}{lcc}
\hline Suxeito & Sexo & Idade \\
\hline Suxeito 1 & Muller & 10 \\
Suxeito 2 & Home & 6 \\
Suxeito 3 & Home & 7 \\
\hline
\end{tabular}

\section{Instrumentos}

Realízase unha avaliación inicial e final do proceso lecto escritor dos suxeitos para o que se empregan o seguinte instrumento:

Test TALE ou Test de Análise da Lectoescritura, de J. Toro e M. Cervera (1984), é unha proba de aplicación individual que ten como obxectivo a avaliación dos niveis xerais e as características específica da lectura e a escritura de calquera neno nun momento dado do proceso de adquisición de tales condutas.

Esta proba está formada por dous subtests:

1. Subtest de Lectura, que está dividido á súa vez en cinco subtests:

a) Lectura de Letras:Componse dunha lista de letras en maiúsculas e outra en minúsculas, medíndose o tempo investido na súa lectura.

b) Lectura de Sílabas: O suxeito debe ler unha lista de sílabas, medíndose tamén o tempo.

c) Lectura de Palabras: O neno debe ler unha lista de palabras, medíndose igualmente o tempo.

d) Lectura de Textos: Elíxese un texto en función do nivel escolar do suxeito, de $1^{\circ}$ a $4^{\circ}$ de Primaria que se debe ler en voz alta, rexistrándose o tempo investido niso.

e) Comprensión Lectora: Elíxese un texto de Lectura Comprensiva tamén en función do nivel escolar do neno, de $1^{\circ}$ a $4^{\circ}$ de Primaria e posteriormente efectuanse dez preguntas para determinar a súa comprensión.

2. Subtest de Escritura, que está dividido á súa vez en tres subtests:

a) Copia: $O$ neno debe copiar escribindo en letra minúscula o modelo facilitado, debendo cronometrarse a duración total do subtest.

b) Ditado: Tamén hai que elixir o texto a ditar en función do nivel escolar do neno, de $1^{\circ}$ a $4^{\circ}$ de Primaria Débense ditar frases, non palabras.

c) Escritura Espontánea: Dicir ao neno: "Agora farás unha redacción. Escribe aquí todo o que se che ocorra sobre o que ti queiras".

Así mesmos emprégase un programa de aprendizaxe da lectura global apoiado en imaxes e partindo dos centros de interese dos suxeitos.

As palabras coas que se empeza a traballas son xeralmente:

- Nomes de familiares: Papá, mamá, irmán, tío, tía...

- Nomes de alimentos favoritos: Pan, auga, chocolate, galleta, arroz, ovo, salchicha, xeado, zume, leite, Cola-cao...

- Nomes de prendas de vestir: Abrigo, pantalón, zapatos, zapatos, saia, camiseta, camisa...

- Xogos e xoguetes: pelota, coches, boneca, puzzle, conto...

Posteriormente introdúcense verbos de acción: Estar, comer, comprar, ver... e adxectivos de diversos tipos: alto, baixo, guapo, vermello, azul, gris...

Trabállase con láminas nas que debe ir emparellando cada imaxe coa súa palabra. Así mesmo empréganse libretas organizadoras con horarios nas que se sinala que se vai facer en cada intre da xornada. Na cociña emprégase un panel no que día a día os suxeitos deben ir marcando coa imaxe e palabra que alimentos teñen no seu menú. Nos armarios etiquétanse as estanterías cos nomes das prendas de vestir que conteñen. Nas habitacións dos nenos etiquétanse os xoguetes e os mobles cos seus nomes para que teñan visible sempre a referencia do obxecto real.

\section{Procedemento}

A continuación recollemos os pasos que se seguiron para este traballo.

En primeiro lugar realízase unha avaliación inicial empregando o test de lectura TALE (1984). Para elo préstase especial atención as partes relacionadas coa lectura de letras, sílabas e palabras dado que aínda non se rexistra lectura de frases nin de textos. En relación á escritura préstase especial atención á copia-

En segundo lugar procédese a efectuar unha intervención na lectura empregando un programa baseado métodos globais e apoiado por estratexias en contornas naturais. Este programa realízase no fogar dos rapaces cunha duración de 2 horas á semana durante 6 
meses. Ademais efectuase unha intervención coordinada co centro educativo no que se seguen as mesmas estratexias que o profesorado de Audición e linguaxe e Pedagoxía terapéutica. En todos os casos existe un apoio de 2 horas semanais de cada un deles.

En terceiro lugar efectúase a avaliación final empregando o test de lectura TALE (1984) para determinar os cambios que o programa acadou.

\section{Resultados}

A continuación, nas táboas 2,3 e 4 recóllense os resultados obtidos polos suxeitos na avaliación inicial e final dentro de cada unha das probas de lectura:

Táboa 2.

Lectura de letras maiúsculas

\begin{tabular}{lcc}
\hline Suxeitos & Avaliación inicial & Avaliación final \\
\hline Suxeito 1 & 27 & 30 \\
Suxeito 2 & 25 & 30 \\
Suxeito 3 & 26 & 30 \\
\hline
\end{tabular}

Táboa 3.

Lectura de sílabas

\begin{tabular}{lcc}
\hline Suxeitos & Avaliación inicial & Avaliación final \\
\hline Suxeito 1 & 3 & 12 \\
Suxeito 2 & 4 & 9 \\
Suxeito 3 & 2 & 5 \\
\hline
\end{tabular}

Táboa 4.

Lectura de palabras

\begin{tabular}{lcc}
\hline Suxeitos & Avaliación inicial & Avaliación final \\
\hline Suxeito 1 & 0 & 15 \\
Suxeito 2 & 0 & 12 \\
Suxeito 3 & 0 & 9 \\
\hline
\end{tabular}

Na táboa 5 e 6 móstranse os resultados relativos á copia de sílabas e palabras sen erros. É preciso destacar que nalgúns casos o suxeitos realizan unha copia alterando a orde dos fonemas ou omitindo algúns deles polo que se consideran erros e non puntúan na avaliación final. En xeral a copia de sílabas require menor esforzo e obtén mellores resultados que a de palabras.

Táboa 5.

Copia sílabas

\begin{tabular}{lcc}
\hline Suxeitos & Avaliación inicial & Avaliación final \\
\hline Suxeito 1 & 10 & 15 \\
Suxeito 2 & 8 & 14 \\
Suxeito 3 & 9 & 15 \\
\hline
\end{tabular}

Táboa 6.

Copia palabras

\begin{tabular}{lcc}
\hline Suxeitos & Avaliación inicial & Avaliación final \\
\hline Suxeito 1 & 8 & 14 \\
Suxeito 2 & 5 & 12 \\
Suxeito 3 & 4 & 13 \\
\hline
\end{tabular}

\section{Discusión}

A lectura empregando o método global parte de unidades lingüísticas con significado. Por iso, o ensino da lectura non se centra nos seus inicios na decodificación grafema-fonema, senón no estudo de unidades complexas con significado (frases, palabras) para que ao final do proceso o suxeito sexa quen de coñecer e distinguir os elementos máis simples (sílabas e letras) en base á descomposición desas unidades significativas. Este método defende que a aprendizaxe da lectura debe partir do estudo de unidades complexas con significado, unha visión global das palabras ou as frases.

Este tipo de métodos teñen vantaxes como que se parte dunha idea precisa e completa onde o ensino é activo ademais as impresións dos suxeitos cara á lectura son positivas e reforzantes, xa que desde o principio teñen a sensación de que saben ler. Iso resulta especialmente significativo nas persoas que presentan TEL debido a que ás veces fracasaron empregando outro tipo de métodos que lle supuxeron un gran esforzo mentres que cos métodos globais observan que avanzan e aprenden a bo ritmo. Iso repercute na súa autoestima e calidade de vida.

Este tipo de aprendizaxes pódense realizar coordinando o traballo coa contorna natural dado que os suxeitos coñecen a súa utilidade e o significado das palabras o que axuda a fixalos. Os resultados obtidos no estudo validan a hipótese de que os programas baseados en lectura global mellora o proceso lecto-escritor de suxeitos con TEL. Con todo serán necesarias mais investigacións respecto diso para tentar establecer pautas xerais que permitan mellorar estes procesos.

\section{Referencias}

Acosta, V. M., Ramírez, G. M. e Hernández, S. (2013). Identificación y clasificación de alumnado con Trastorno Específico del Lenguaje (TEL). Revista de Logopedia, Foniatría y Audiología, 33, 157---164.

Buiza-Navarrete, J. J., Adrián-Torres, J. A. e GonzálezSánchez, M. (2007). Marcadores neurocognitivos en el trastorno específico del lenguaje. Revista de Neurología, 44(6), 326---333.

Castro-Rebolledo, R., Giraldo-Prieto, M., HincapiéHenao, L., Lopera, F. e Pineda, D. A. (2004). Trastorno específico del desarrollo del lenguaje: una aproximación teórica a su diagnóstico, etiología y manifestaciones clínicas. Revista de Neurología, 39(12), 1173---1181.

Catts, H.W., Fey, M.E., Tomblin, J.B., e Zhang, Z. (2002). A longitudinal investigation of reading outcomes in children with language impairments. Journal of Speech, Language, and Hearing Research,45, 1142-1157.

Henry, L. A., Messer, D. J. e Nash, G. (2012). Executive functioning in children with specific language impairment. Journal of Child Psychology and Psychiatry, 53(1), 37---45.

Hill, E. L. (2001). Non-specific nature of specific language impairment:A review of the literature with regard to concomitant motor impairments. International Journal of Language and Communication Disorders, 36(2), 149---171. 
Montgomery, J. W. (2000). Verbal working memory and sentence comprehension in children with specific language impairment. Journal of Speech Language, 43, 293---308.

Montgomery, J. W. e Evans, J. L. (2009). Complex sentence comprehension and working memory in children with specific language impairment. Journal of Speech, Language, and Hearing Research, 52(2), 269---288.

Rapin, I. D. e Allen, D. A. (1987). Developmental dysphasia and autism in preschool children: Characteristics and subtypes. En J. Martín, P. Martín, P. Fletcher, P. Grunweil, \& D. Hall (Eds.), Proceedings of the first international symposium on specific speechand language disorders in children (pp. 20---35). London: Afasic.

Snowling, M., Bishop, D. V. M., e Stothard, S. E. (2000). Is pre-school language impairment a risk factor for dyslexia in adolescence? Journal of Child Psychology and Psychiatry, 41, 587-600.

Toro, J. e Cervera, M. (1984). TALE. Test de Análisis de Lectoescritura. Madrid: Visor.

Whitehouse A, Bishop D, Ang Q, Pennell C, e Fisher S. (2011) CNTNAP2 variants affect early language development in the general population. Genes, Brain and Behavior. 10(4):451-456.

Williams, D., Stott, C. M., Goodyer, I. M. e Sahakian, B. J. (2000). Specific language impairment with or without hyperactivity: Neuropsychological evidence for frontostriatal dysfunction. Developmental Medicine \& Child Neurology, 42(6), 368. 